\title{
Endovascular coil embolization for acute management of traumatic pulmonary artery pseudoaneurysm
}

\author{
Mark Block, MD, ${ }^{\mathrm{a}, \mathrm{b}}$ Todd Lefkowitz, BS, ${ }^{\mathrm{b}}$ James Ravenel, MD, ${ }^{\mathrm{c}}$ Stuart Leon, MD, and Chris Hannegan, MD, \\ Charleston, SC
}

\section{Clinical Summary}

A 40-year-old woman with a history of depression presented with a self-inflicted gunshot wound to the left side of the chest. On arrival, she was alert and hemodynamically stable. An entrance and an exit wound were identified on the anterior and posterior chest, and there were no breath sounds on the left. A chest tube was placed and immediately drained of $360 \mathrm{~mL}$ of fresh blood. A chest $\mathrm{X}$-ray film showed multiple rib fractures and opacification of the left side of the chest without mediastinal shift. Chest computed tomography (CT) with intravenous contrast showed extensive pulmonary contusion and consolidation, a small pleural effusion, a path of lung parenchymal destruction consistent with a bullet track, and 3 distinct areas of well-defined increased attenuation along the track suggestive of hemorrhage (Figure 1). The patient remained hemodynamically stable, and chest tube output was less than 100 $\mathrm{mL} / \mathrm{h}$, but she had occasional hemoptysis of fresh blood. Chest CT 18 hours later showed interval enlargement of the 3 areas of hemorrhage that now assumed clearly spherical shapes. Pulmonary angiography identified 3 pseudoaneurysms, 1 arising from the inferior lingular artery and 2 arising from the superior segmental artery (Figure 2). The patient remained hemodynamically stable with minimal chest tube output and no change in hemoptysis. Thoracotomy was considered, but a decision was made to attempt embolization.

Each injured vessel was selectively catheterized, and Cook embolization coils (Cook, Inc, Bloomington, Ind) were placed into each extraluminal pseudoaneurysm cavity until the cavity would no longer accept a coil. Postembolization angiography demonstrated complete cessation of flow in 2 of the 3 pseudoaneurysms, with minimal residual flow in the third. Chest CT the next day demonstrated complete thrombosis of 2 of the 3 pseudoaneurysms and greatly diminished flow through the third. The patient remained stable, and her hemoptysis subsided. The chest tube was removed on day 5 . On day 8 , the patient was transferred to the inpatient psychiatric hospital. She was discharged home 17 days after the injury.

\footnotetext{
From the Department of Surgery, ${ }^{a}$ Ralph H. Johnson VA Medical Center, Charleston, SC, and the Departments of Surgery ${ }^{\mathrm{b}}$ and Radiology, ${ }^{\mathrm{c}}$ Medical University of South Carolina, Charleston, SC.

Received for publication Jan 27, 2004; revisions requested March 4, 2004; accepted for publication March 22, 2004.

Address for reprints: Mark Block, MD, Division of Cardiothoracic Surgery, 96 Jonathan Lucas St, 409 CSB, Medical University of South Carolina, Charleston, SC 29425 (E-mail: blockm@musc.edu).

J Thorac Cardiovasc Surg 2004;128:784-5

$0022-5223 / \$ 30.00$

Copyright @ 2004 by The American Association for Thoracic Surgery

doi:10.1016/j.jtcvs.2004.03.028
}

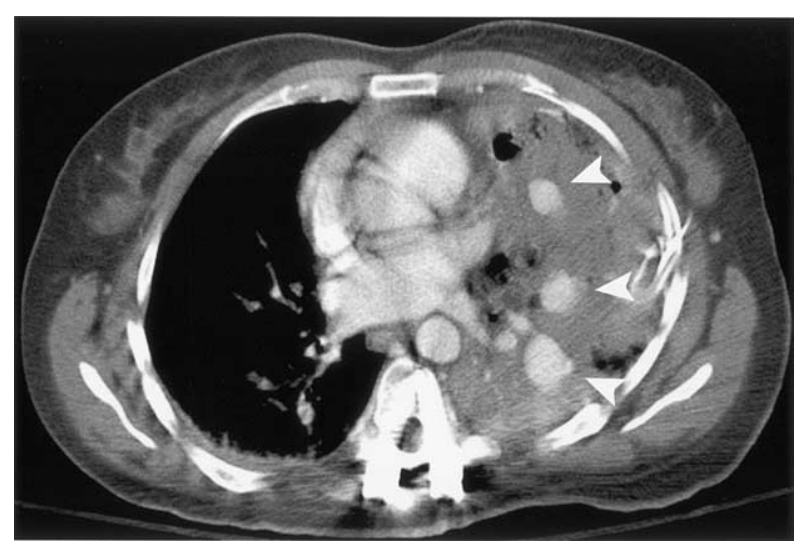

Figure 1. Initial chest CT scan showing consolidation of the left lung and 3 areas of spherical increased attenuation along the bullet track (arrowheads).

Chest CT 1 month later showed continued improvement in left lung aeration, with no evidence of blood flow through any of the pseudoaneurysms. Eight weeks later, the patient felt well and had no hemoptysis. A chest x-ray film showed a near-normal left lung and pleural space.

\section{Discussion}

Pulmonary artery pseudoaneurysms are uncommon but carry a significant risk of rupture and death. They are identified most often as a complication of pulmonary artery catheter use and are estimated to occur at a rate of $0.5 \% .^{1}$ Other nontraumatic causes include Bechet disease, Marfan syndrome, fungal infection, and tuberculosis. Traumatic pulmonary artery pseudoaneurysms are extremely rare despite the large number of patients with chest trauma. We identified 16 cases in the literature. ${ }^{2-4}$ Of the 12 reported since 1963, 5 were diagnosed during the patient's initial hospitalization (4-14 days after injury), and 7 were diagnosed between 14 days and 30 years later. The clinical presentation is highly variable. In the acute setting, as in our case, hemoptysis and suspicious radiographic findings suggest the diagnosis. In the delayed setting 3 patients presented with hemoptysis, 2 were asymptomatic, 1 had dyspnea, and 1 had chest pain. There are no reports of massive hemoptysis and death from an unrecognized or untreated traumatic pulmonary artery pseudoaneurysm, and the only death among the 12 cases reported since 1963 was from complications after pneumonectomy. ${ }^{5}$ However, given the experience with pulmonary artery pseudoaneurysms from other causes, prompt diagnosis and therapy seem the most prudent management strategy. 


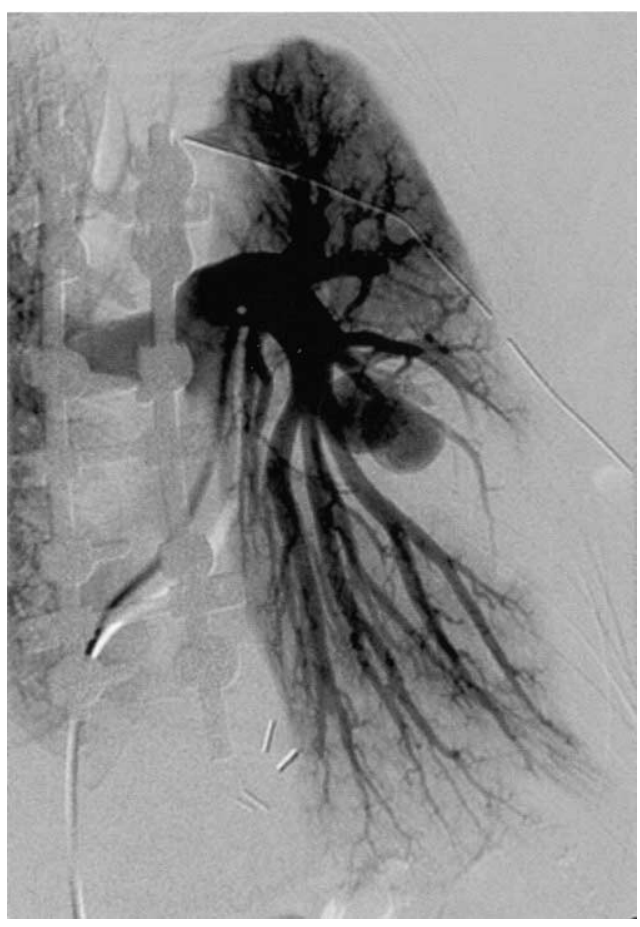

Figure 2. Pulmonary arteriogram demonstrating 2 spherical opacifications diagnostic of pseudoaneurysms.

Embolization was first reported by Savage and colleagues, ${ }^{2}$ but because of persistent hemoptysis, a lobectomy was performed. Their patient presented 30 years after the injury. de Jonge and coworkers $^{3}$ reported successful embolization therapy in a patient who was discharged from the hospital with a clearing chest x-ray film but who presented with dyspnea 14 days after the injury. Our patient was given a diagnosis early, and embolization enabled us to safely continue observation and avoid a pulmonary resection. A chest x-ray film 2 months later showed near-complete resolution of intrapleural and intraparenchymal blood and no evidence of a persistent aneurysm. The interval between injury and therapy might account for the success of embolization in our and de Jonge and coworkers' ${ }^{3}$ cases. With a short interval, tissue factors that promote healing are likely abundant. However, in the case of Savage and colleagues, ${ }^{2}$ it is likely that the pseudoaneurysmal environment was completely mature and fibrotic. Embolization can be a safe and effective management strategy for traumatic pulmonary artery pseudoaneurysms that are discovered soon after the injury.

\section{References}

1. Poplausky MR, Rozenblit G, Rundback JH, Crea G, Maddineni S, Leonardo R. Swan-Ganz catheter-induced pulmonary artery pseudoaneurysm formation: three case reports and a review of the literature. Chest. 2001;120(6):2105-11.

2. Savage C, Zwischenberger JB, Ventura KC, Wittich GR. Hemoptysis secondary to pulmonary pseudoaneurysm 30 years after a gunshot wound. Ann Thorac Surg. 2001;71(3):1021-3.

3. de Jonge I, Vahl A, van der Hulst V. Coil embolization of a left pulmonary artery pseudoaneurysm after penetrating injury. J Endovasc Ther. 2003;10(3):681-3.

4. Donaldson B, Ngo-Nonga B. Traumatic pseudoaneurysm of the pulmonary artery: case report and review of the literature. Am Surg. 2002; 68(5):414-6.

5. Dillon WP, Taylor AT, Mineau DE, Datz FL. Traumatic pulmonary artery pseudoaneurysm simulating pulmonary embolism. AJR Am J Roentgenol. 1982;139(4):818-9. 